\title{
Anal anomalies: an uncommon feature of velocardiofacial (Shprintzen) syndrome?
}

\author{
S Worthington, A Colley, K Fagan, Kang Dai, A H Lipson*
}

\begin{abstract}
We report three cases of velocardiofacial syndrome (VCFS) with anal anomalies who have deletions of the 22 q11 region and a further case where the proband has VCFS clinically and her father has an anal anomaly. It is important to consider VCFS in the differential diagnosis of children with anal anomalies and to look for other features of the syndrome, such as asymmetrical crying facies, submucous cleft of the palate, developmental delay, cardiac anomalies, and hypoparathyroidism. (F Med Genet 1997;34:79-82)
\end{abstract}

Keywords: anal anomalies; velocardiofacial syndrome; 22q11 deletion.

The 22q11 deletion disorders include velocardiofacial syndrome (VCFS), ${ }^{1}$ the DiGeorge sequence (DGS), ${ }^{23}$ conotruncal anomaly face syndrome, ${ }^{4}$ Cayler's cardiofacial or asymmetrical crying facies syndrome, ${ }^{5}$ and "CATCH 22 ". ${ }^{6}$ They consist of a wide spectrum of clinical manifestations some of which are explained by abnormal migration of neural crest cells. ${ }^{7}$

Anal anomalies occur in approximately 1 in 5000 live births. ${ }^{8}$ They occur in many syndromes and have been commonly described in association with other malformations. ${ }^{9}$ Cardiovascular (CVS) anomalies, most commonly ventricular septal defect and tetralogy of Fallot, are reported to occur in $7-22 \%$ of cases with imperforate anus. ${ }^{10}$ Other associated anomalies include spina bifida, genitourinary abnormalities, limb defects, and tracheo-oesophageal fistulae. ${ }^{910}$ Anal anomalies have been reported infrequently in the $22 \mathrm{q} 11$ deletion disorders. ${ }^{611-13}$

We report three cases of VCFS with anal anomalies who have deletions of the $22 \mathrm{q} 11$ region detected using fluorescent in situ hybridisation (FISH). A further case is presented where the proband has VCFS clinically and her father an anal anomaly and mental retardation, presumably because of VCFS.

\section{Case reports}

CASE 1

Case 1, a male, the second child of unrelated parents, was born at 38 weeks' gestation by caesarean section with a birth weight of $2640 \mathrm{~g}$ ( 10 th centile), length $40 \mathrm{~cm}$ ( $<3$ rd centile), and OFC $32.8 \mathrm{~cm}$ (10th centile). The pregnancy was uneventful. Chromosomal analysis of amniocytes at 16 weeks' gestation, performed for advanced maternal age, was reported as a normal male karyotype. The neonatal period was complicated by hypotonia and feeding difficulties and gastro-oesophageal reflux. Constipation owing to anal stenosis was a problem from the first month of age. At 7 months of age he underwent an anoplasty which was successful in treating the constipation.

He had significant global developmental and expressive speech delay with a normal hearing assessment. A skeletal survey showed spina bifida occulta. At 4 years of age he was referred to a child development unit where the diagnosis of VCFS was suggested. Review by a geneticist confirmed facial dysmorphic features (fig 1) of micrognathia, almond shaped palpebral fissures, deficient alae nasi, broad nasal bridge, prominent dysplastic ears, and a short, hypotonic palate with a single uvula. Cardiovascular examination was normal and his height was on the 3rd centile. A diagnosis of VCFS was made clinically and FISH studies with the Oncor N25 probe confirmed a deletion of the chromosome 22q11 region. The family history was unremarkable with neither parent having VCFS clinically. FISH studies are not available on the parents.

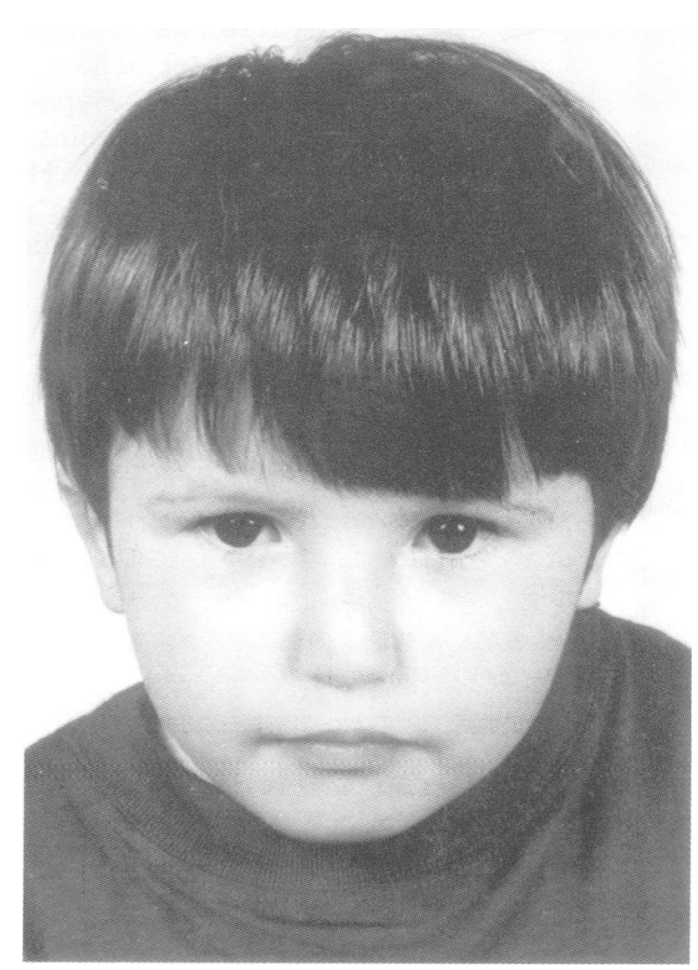

Figure 1 Case 1: congenital anal stenosis. Note micrognathia, almond shaped palpebral fissures, deficient alae nasi, and broad nasal bridge. 


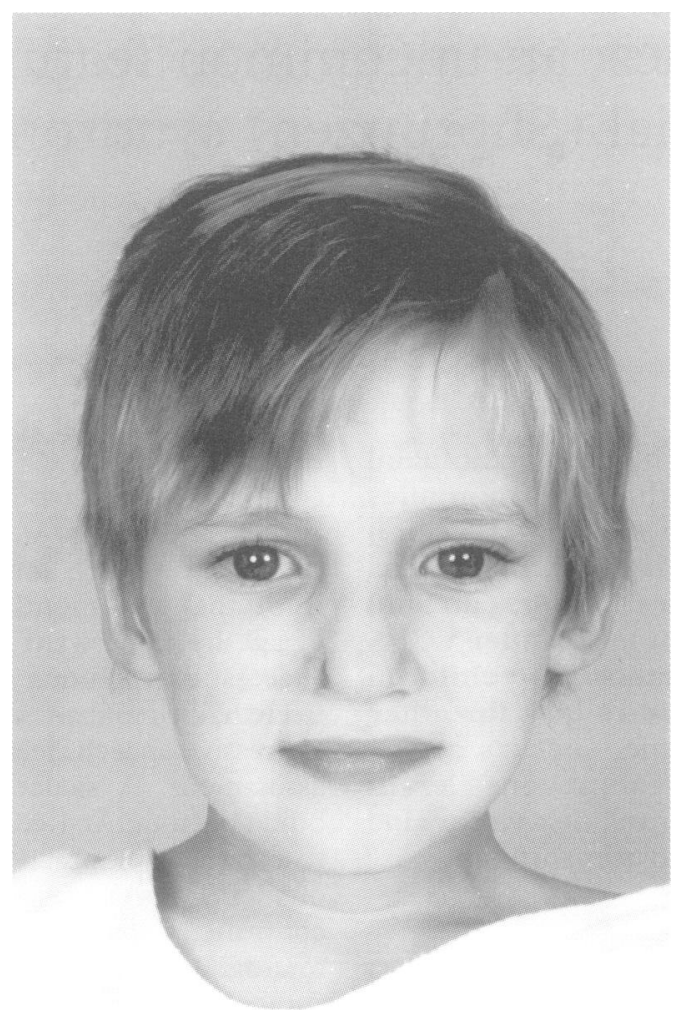

Figure 2 Case 2: covered anus with perineal fistula. Note almond shaped palpebral fissures, maxillary and mandibular hypoplasia, and small dysplastic ears.

CASE 2

Case 2, a 5 year old male, the second child of non-consanguineous parents, was born at 40 weeks' gestation by normal vaginal delivery. Labour was complicated by fetal distress with meconium stained liquor. Apgar scores were 5 and 7 at one and five minutes respectively. $\mathrm{He}$ was resuscitated at birth, then intubated and ventilated for 24 hours. Birth weight was $3000 \mathrm{~g}$ (10th centile). Hypothyroidism was detected by newborn screening and treatment with thyroxine was started. He was noted to have a covered anus and a perineal fistula at birth, which were treated surgically by anoplasty and

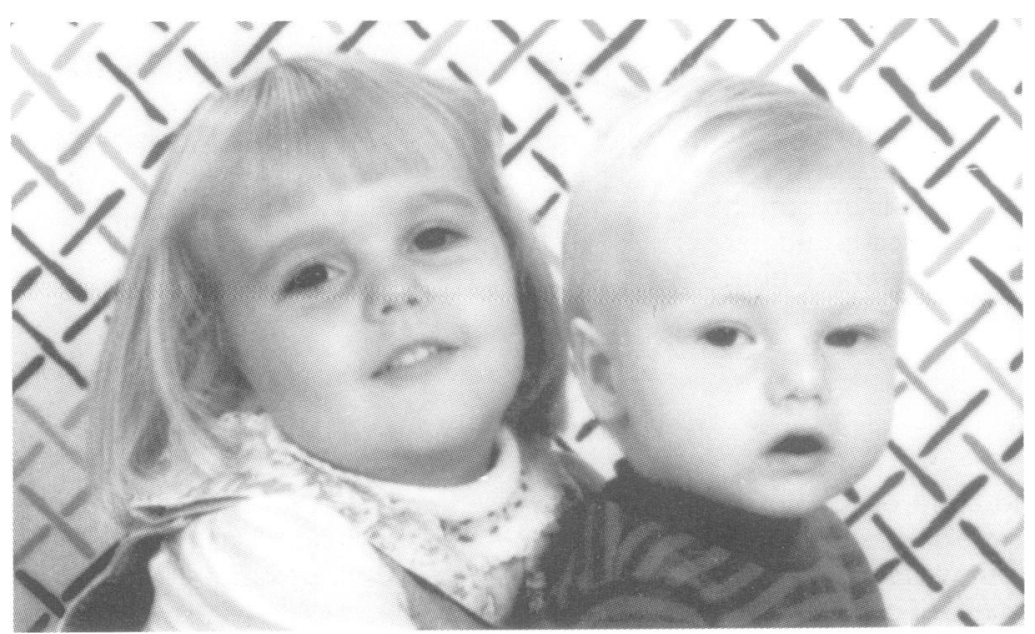

Figure 3 Case 3: congenital anal stenosis. His older female sib (left) is shown to indicate familial resemblance. Note almond shaped palpebral fissures, myopathic facies, broad nasal bridge, and deficient alae nasi. excision of the fistula. The family history was unremarkable.

His subsequent course was complicated by slow growth, and expressive speech delay with hypernasal speech. He was referred to a cleft palate clinic for speech review where he was seen by a geneticist who noted myopathic facies, deficiency of the alae nasi, almond shaped palpebral fissures, maxillary and mandibular hypoplasia, and small dysplastic ears (fig 2). His palate was short and the uvula grooved. Cardiovascular examination was normal and his height was on the 3 rd centile. These features were consistent with VCFS and FISH studies with the Oncor $\mathrm{N} 25$ probe confirmed a deletion of the chromosome $22 \mathrm{q} 11$ region. His parents did not have VCFS clinically; FISH studies of the parents are not available. At 5 years of age, during induction of anaesthesia for pharyngoplasty, a diagnosis of anterior laryngeal web, subglottic stenosis, and thickened cricoid cartilage was made.

\section{CASE 3}

Case 3 was the second child of non-consanguineous, healthy, Dutch parents. He was born at 40 weeks' gestation by normal vaginal delivery following an uneventful pregnancy. Gastro-oesophageal reflux, poor oral motor function, and hypotonia were significant problems from birth. At 3 months of age he developed constipation which persisted despite medical treatment. Anal stenosis was diagnosed at 10 months of age and was initially treated with anal dilatation but without success. On examination under anaesthesia there was a tight fibrous anal ring which required surgical treatment. Surgery consisting of sphincterotomy and anoplasty was performed at 17 months of age.

At 3 years of age, he was referred to a geneticist for syndrome identification because of severe expressive speech delay, mild global developmental delay, and hypotonia. He had hypernasal speech with a bifid uvula and hypotonic palate. His height, weight, and OFC measurements were all on the 50th centile for age. His facial appearance consisted of almond shaped palpebral fissures, epicanthic folds, a broad nasal bridge with small alae nasi, and a smooth philtrum, as shown in fig 3 . He had joint laxity and tapering fingers with narrow distal phalanges. His ears were normally situated but had thickened helices. Hearing tests were normal. A sacral pit was noted but $x$ rays showed no associated abnormalities of the vertebrae. An echocardiogram was normal apart from an aberrant subclavian artery. A diagnosis of VCFS was made clinically and FISH studies with the Oncor N25 probe confirmed a deletion (de novo) of the chromosome 22q11 region.

His older sister was healthy with no learning problems. There was a strong familial facial appearance (fig 3).

\section{CASE 4}

Case 4, a 4 year old female, the second child of a young, non-consanguineous couple, was 
born at term following an uneventful pregnancy. She was delivered by caesarean section for cephalopelvic disproportion and fetal distress. Apgar scores were 9 and 9 at one and five minutes respectively. Birth weight was $3370 \mathrm{~g}$ (50th centile), length $53 \mathrm{~cm}$ (90th centile), and OFC $34 \mathrm{~cm}$ (50th centile). The neonatal period was complicated by hypoglycaemia, transient hypoparathyroidism, and cyanosis associated with a cardiac murmur. The absent pulmonary valve syndrome consisting of an absent pulmonary valve, pulmonary artery aneurysm, ventricular septal defect, and bronchomalacia was diagnosed on day 3. This cardiovascular anomaly was associated with a right aortic arch.

Surgery consisted of homograft reconstruction of the pulmonary artery and closure of the ventricular septal defect at 5 months of age. The thymus gland was absent at operation but subsequent $T$ cell subsets were normal. At 16 months of age she was seen in the immunology clinic because of poor weight gain associated with recurrent upper respiratory tract and ear infections. Facial dysmorphic features included an expressionless face, small mouth, almond shaped palpebral fissures, midface hypoplasia, and protuberant ears with absent ear lobes. Short stature was present with height less than the 3 rd centile. At 22 months of age when seen by a geneticist she also had gross motor and expressive speech delay and a clinical diagnosis of VCFS was made.

The family history was complex. A sib was developmentally delayed with hypernasal speech. The father had an imperforate anus and attended a special school because of learning difficulties. Congenital heart disease, imperforate anus, and intellectual handicap occurred in other family members. Karyotype studies of the proband were normal, but FISH studies were not performed because the family has been lost to follow up.

\section{Discussion}

VCFS was described in 1978 by Shprintzen et $a l^{14}$ and was characterised by a cleft palate in association with congenital heart disease, facial dysmorphism, and learning disabilities. ${ }^{14}$ The phenotypic spectrum was later expanded as the variability of this syndrome was recognised..$^{15}$ The discovery that deletions of chromosome $22 \mathrm{q} 11$ were associated with DGS, and that DGS and VCFS were a spectrum of the same disorder led not only to further expansion of the clinical spectrum but to hypotheses regarding the role of genes from this chromosome region in neural cell migration and the pathogenesis of the associated birth defects. ${ }^{16}$

The cases presented have the typical facial features of VCFS and abnormalities of the palate resulting in hypernasal speech. The children with anal anomalies do not have cardiovascular anomalies, although the latter is a common manifestation of VCFS. All except case 4 have proven 22q11 deletions. Case 4 has the typical facial features and cardiovascular lesion but it is her retarded father who has an anal anomaly. Anal anomalies have been infrequently reported in children who have fea- tures of the 22q11 deletion syndromes. An infant with a clinical diagnosis of DGS was reported with a ventricular septal defect (VSD), cleft lip and palate, bilateral hydroureters, hypocalcaemia, and anal atresia. ${ }^{11}$ Anteriorly placed anus was reported by Wilson et at in one of 44 cases with a 22q11 deletion, McDonaldMcGinn $e t a l^{12}$ in two of 52 cases with VCFS, and DeSilva et $a l^{13}$ in one of three cases of familial 22q deletion. Deletions of the chromosome $22 \mathrm{q} 11$ region have also been reported in Cayler syndrome, ${ }^{5}$ the association of congenital hypoplasia of the depressor anguli oris muscle with congenital heart disease. Imperforate anus and anal stenosis have occurred in four patients with Cayler syndrome; however, they were not investigated for the possibility of a $22 \mathrm{q} 11$ deletion. ${ }^{178}$

Anal anomalies occur in many syndromes including the VATER association, ${ }^{19}$ caudal regression syndrome, ${ }^{20} \mathrm{FG}$ syndrome, ${ }^{21}$ cat eye syndrome (CES), ${ }^{22}$ Kabuki syndrome, ${ }^{23}$ Townes-Brocks syndrome, ${ }^{24}$ and Opitz G syndrome. ${ }^{25}$ CES is characterised by ocular coloboma, anal atresia, preauricular skin tags and pits, heart defects, and facial dysmorphic features. ${ }^{22}$ CES is caused by partial tetrasomy for the $22 \mathrm{q} 11.2$ region. ${ }^{22}$ Although DGS and CES map to the same cytogenetic region, the distal boundary of the CES critical region is proximal to that of DGS. ${ }^{22}$ The significance of the close proximity of these gene loci, one deleted, the other overexpressed, in the pathogenesis of anal and cardiovascular anomalies is uncertain. The 22q11 deletion syndromes and CES share some features in common. McPherson et $a l^{26}$ reported a girl with features of cat eye syndrome but with a normal karyotype. She had an imperforate anus, facial dysmorphism, iris colobomata, bilateral cleft lip, hip dislocation, and talipes calcaneovalgus. Her father had milder but similar features with a broad nasal bridge, low set, posteriorly rotated ears, mild micrognathia, anal stenosis, and brachydactyly. VCFS could be considered as a possible diagnosis for this family.

The Opitz G syndrome is an autosomal dominant disorder characterised by facial dysmorphism and multiple congenital anomalies. Many of these features also occur in VCFS. Anal anomalies have been reported in this syndrome. ${ }^{25}$ Christodoulou et $a l^{77}$ described a baby with Opitz G syndrome who had a hoarse cry, hypertelorism, low set ears with a prominent crus helix, a cleft of the soft palate, patent ductus arteriosus, hypotonia, hypospadias, undescended testes, and an imperforate anus. This infant had a ring chromosome 22 karyotype on $G$ banding reported as $46, X Y$, $r(22)(p 13 ; q 13.3)$. It is not known if the 22q11 region was deleted as more detailed analysis of the breakpoints was not available and the patient is now dead. McDonald-McGinn et al ${ }^{12}$ reported three cases with Opitz G syndrome that had a 22q11.2 deletion shown by FISH studies. None of these cases, however, had anal anomalies.

The structures involved in the $22 \mathrm{q} 11$ deletion syndromes, the parathyroids, thymus, face, and the conotruncal region of the heart are derived 
from the pharyngeal pouches. The neural crest makes important mesenchymal contributions to the derivatives of the pharyngeal pouches and this led to the hypothesis that many of the manifestations of the DGS and VCFS were caused by abnormalities of neural cell migration. ${ }^{816}$ The development of the anorectal region may also be influenced by neural crest cell migration. ${ }^{28}$ Most anorectal anomalies result from abnormal development of a wedge of mesenchyme called the urorectal septum. ${ }^{29}$ It is possible that the pathogenesis of anomalies in VCFS is related to a defect in mesenchyme cell migration. The defect could be in the programming of cell migration, an abnormality of the cell matrix that contains the migrating cells, ${ }^{28}$ or because of a faulty cell adhesion molecule.

Deletions of 22q11 result in a variable clinical picture which may include anal anomalies. Variation in the phenotype is considerable, and the presence of cleft palate or cardiovascular anomalies is not obligatory. ${ }^{30}$ Only one case had a cardiac anomaly and two a submucous cleft of the palate. Indeed the initial presentation in these cases was because of the anal anomalies. Constipation is not an uncommon symptom in children with developmental delay and hypotonia. Anal anomalies such as congenital stenosis need to be considered in VCFS as effective treatment is available. Similarly, awareness of the occurrence of anal anomalies in VCFS may lead to the recognition of previously undiagnosed anomalies such as submucous cleft of the palate, developmental delay, cardiac anomalies, and hypoparathyroidism. The mechanism by which deletion of the genes in the 22q11 region causes anal anomalies with such a variable clinical picture is unknown, but may be related to an abnormality of mesenchymal cell migration.

We thank the children and their families for their cooperation our colleagues for referring the cases, and Pixie Maloney an Amir Saguiguit for the photographs. This work was supported by a National Health and Medical Research Council of Australi Developmental Grant. We report with regret the untimely death, since this paper was written, of Tony Lipson. We would like to dedicate this paper to Tony Lipson to reflect his enthusiasm and contribution to the understanding of VCFS and his dedication to children with VCFS and their families.

1 Driscoll DA, Spinner NB, Budarf ML, et al. Deletions and microdeletions of $22 \mathrm{q} 11$ in velo-cardio-facial syndrome. Am 7 Med Genet 1992;44:261-8.

2 De la Chapelle A, Herva R, Koivisto M, Aula O. A deletion in chromosome 22 can cause DiGeorge syndrome. Hum Genet 1981;57:253-6.

3 Scambler PJ, Kelly D, Lindley E, et al. Velo-cardio-facia syndrome associated with chromosome 22 deletions encompassing the DiGeorge locus. Lancet 1992;339:1138-9.

4 Burn J, Takao A, Wilson D, et al. Conotruncal anomaly face syndrome is associated with a deletion within chromosome 22q11. F Med Genet 1993;30:813-17.
5 Giannotti A, Digilio MC, Marino B, Mingarelli R, Dallapiccola B. Cayler cardiofacial syndrome and del 22q11: part of the CATCH 22 phenotype. Am 7 Med Genet 1994; part of the

6 Wilson DI, Burn J, Scambler P, Goodship J. DiGeorge syndrome: part of CATCH 22. F Med Genet 1993;30: 852-6.

7 Webster WS, Johnston MC, Lammer EJ, Sulik KK. Isoretinoin embryopathy and the cranial neural crest: an in vivo and in vitro study. $f$ Craniofac Genet Dev Biol 1986; 6:211-22.

8 Van Mierop LH, Kutsche LM. Cardiovascular anomalies in DiGeorge syndrome and importance of neural crest as

9 Smith E. Incidence, frequency of types, and etiology of anorectal malformations. Birth Defects 1988;24:231-46.

10 Greenwood RD, Rosenthal A, Nadas AS. Cardiovascular malformations associated with imperforate anus. $\mathcal{F}$ Pediatr 1975;86:576-9.

11 Conley ME, Beckwith JB, Mancer JF, Tenckhoff L. The spectrum of the DiGeorge syndrome. F Pediatr 1979;94: 883-90.

12 McDonald-McGinn DM, Driscoll DA, Bason L, et al. Autosomal dominant "Opitz" GBBB syndrome due to a 22q11.2 deletion. Am $\mathcal{Y}$ Med Genet 1995;59:103-13.

13 DeSilva D, Duffty P, Booth P, Auchterlonie I, Morrison N, Dean JC. Family studies in chromosome 22q11 deletion: further demonstration of phenotypic heterogeneity. Clin Dysmorphol 1995;4:294-303.

14 Shprintzen RJ, Goldberg RB, Lewin ML, et al. A new syndrome involving cleft palate, cardiac anomalies, typical facies, and learning disabilities: velo-cardio-facial syndrome. Cleft Palate 7 1978;15:56.

15 Shprintzen RJ, Goldberg RB, Young D, Wolford L. The velo-cardio-facial syndrome: a clinical and genetic analysis. Pediatrics 1981;67:167-72.

16 Scambler P. Deletions of human chromosome 22 and associated defects. Curr Opin Genet Dev 1993;3:432-7.

17 Pape KE, Pickering D. Asymmetric crying facies: an index of other congenital anomalies. $\mathcal{F}$ Pediatr 1972;81:21-30.

18 Cayler GG. Cardiofacial syndrome. Arch Dis Child 1969; 44:69-75.

19 Weaver DD, Mapstone CL, Poa-lo Y. The Vater association. Am 7 Dis Child 1986;140:225-9.

20 Duhamel B. From the mermaid to anal imperforation. The syndrome of caudal regression. Arch Dis Child 1961;36: 152.

21 Romano C, Baraitser M, Thompson E. A clinical followup of British patients with FG syndrome. Clin Dysmorphol 1994;3:104-14.

22 Mears AJ, Duncan AM, Budarf ML, et al. Molecular characterisation of the marker chromosome associated with cat eye syndrome. Am 7 Hum Genet 1994;55:34-42.

23 Schrander-Stumpel C, Meinecke P, Wilson G, et al. The Kabuki (Niikawa-Kuroki) syndrome: further delineation of the phenotype in 29 non-Japanese patients. Eurf Pediatr 1994;153:438-45.

24 Townes PL, Brocks ER. Hereditary syndrome of imperforate anus with hand, foot and ear anomalies. $\mathcal{F}$ Pediatr 1972; 81:321.

25 Wilson GN, Oliver WJ. Further delineation of the G syndrome: a manageable genetic cause of infantile dysphagia. 7 Med Genet 1988;25:157-63.

26 McPherson E, Jones S, Gallien J, Bannerman R. Dominant transmission of imperforate anus, cleft lip, and iris coltransmission of imperforate anus, cleft lip, and
obomas. Dysmorphol Clin Genet 1989;3:79-83.

27 Christodoulou J, Bankier A, Loughnan L. Ring chromosome 22 karyotype in a patient with Opitz (BBBG) syndrome. Am $\mathcal{F}$ Med Genet 1990;37:422-4.

28 Fujimoto T, Hata J, Yokoyama S, Mitomi T. A study of the extracellular matrix protein as the migration pathway of neural crest cell migration in the gut: analysis in human embryos with special reference to the pathogenesis of Hirschsprungs disease. $\not$ Pediatr Surg 1989;24:550-6.

29 Stephens FD. Embryology of the cloaca and embryogenesis of anorectal malformations. Birth Defects 1988;24:177209.

30 Lipson A, Emanuel B, Colley A, Colley P, Fagan K, Driscoll DA. "CATCH 22 " sans cardiac, thymic hypoplasia, cleft palate, and hypocalcaemia: cAtch 22 . A common cause of 22q deficiency? F Med Genet 1994;31:741. 